\title{
Learning About What's “Down There”: Body Image Below the Belt and Menstrual Education
}

\author{
Margaret L. Stubbs and Evelina W. Sterling
}

In Peggy Orenstein's (2016) book Girls and Sex: Navigating the Complicated New Landscape girls' reflections on their emerging sexuality are fumbling; they seem to lack a coherent language for describing their genitals. For example, one high school senior said, "I've never been comfortable with my parts down there" (Orenstein 2016, 65). Another reflected, "A guy is totally aware of what he looks like down there . . but I don't know what they're seeing on me. I can't see it" (Orenstein 2016, 63). Preparation for menarche and its management compels a specific focus for girls on their genital area which has likely not occurred since learning about toileting and personal cleanliness in early childhood. As such, learning about periods could be an opportunity to help girls build a more accurate and positive foundation for understanding and thinking themselves as sexual beings. However, given girls' current reluctance or inability to name or see their genitals, developing agency in self-care or explorations of sexuality is unlikely. While the relationship between sexual behavior and menstruation is more apparent to older females, describing this relationship is challenging in educating young girls about menstruation. Nevertheless, providing an accurate and developmentally appropriate description of this relationship is possible and important in providing support for the development of girls' healthy sexuality. 


\section{Girls’ Developing Sexuality}

Feminist researchers have long provided insight into how best to study and characterize the development of girls' healthy sexuality (Fine 1988; Tolman 2002). This work acknowledges adolescent sexuality as a normative developmental process including recognition of sexual feelings, and exploration of sexual behavior over time (Tolman and McClelland 2011; Fortenberry 2014). Using both quantitative and qualitative methods, some focus on listening to girls as narrators, not just reporters, of their experiences (Tolman 2012). Distinctions between sexual agency and sexual subjectivity (Lamb and Peterson 2012) and the meaning of "empowerment" in the context of neoliberal messages that emphasize individual choice (Bay-Cheng 2015; Tolman, Anderson, and Belmont 2015) are also investigated.

Sexualization and objectification are features of the contemporary US society in which girls develop as sexual beings (American Psychological Association Task Force on the Sexualization of Girls 2007). These cultural features have also been noted as problematic outside of the United States as well (Crawford et al. 2008; Dakanalis et al. 2017). The influence of these features in the United States has been linked to negative attitudes toward menstruation, for example, the wish to eliminate periods (Johnston-Robledo et al. 2003), and more favorable attitudes to contraception that reduces or stops menstruation (Johnston-Robledo et al. 2007). Continuing research must now also address how self-sexualization and self-objectification are endorsed by girls themselves.

Shifting standards around genital appearance also impact girls' sexual body image. Research from developed countries has documented women's dissatisfaction with labia appearance, and the preference among older and younger females for what might be considered a prepubescent, non-descript "Barbie" vaginal area (Schick, Rima, and Calbrese 2011; Sharp, Tiggeman, and Mattiske 2014). This trend has also been widely noted in related public commentary (Bowerman 2017; Rabin 2016). The demand for surgical alteration of the labia, or labiaplasty, has increased dramatically in the United States (American Society for Aesthetic Plastic Surgeons [ASAPS] 2016; American Society of Plastic Surgeons [ASPS] 2016a, 2016b). In 2016, females aged 19-34 accounted for nearly half of all labia surgeries. While about $5 \%$ were performed on females under the age of 18 , an increase in labiaplasty for these girls has grown since 2014 (ASAPS 2014, 2015, 2016).

Controversy surrounds the necessity for labia surgery. The wide variability of clitoral and labial presentation has been documented as normative (Lloyd et al. 2005). Further, no standardized criteria to define the medical need for labia surgery currently exist (Motakef et al. 2015). Aesthetic and plastic surgeons espouse women's (and girls') right to choose genital surgeries, including labiaplasty, and report client satisfaction after these procedures (Goodman et al. 2016; Hardwick-Smith 2011). The potential of therapeutic labiaplasty has also been acknowledged as an approach to curbing 
non-therapeutic female genital alteration where this is commonly practiced (Arora and Jacobs 2016). Nevertheless, the American College of Obstetrics and Gynecology [ACOG] $(2007,2017)$ argue against labiaplasty unless medically necessary for adolescent females under 18 .

Some researchers identify easy access to pornography featuring hairless female genitalia and tucked-in labia minora as contributing to the demand for labiaplasty (Mowet et al. 2015). However, females' lack of awareness of the wide variation in genital appearance has also been named as contributing (Lloyd et al. 2005; Renganathan, Cartwright, and Cardozo 2009). It seems girls are aware of popular genital appearance norms, but unaware of the wide variation in typical, healthy female genital anatomical structure. Because learning and menstruation does not address this gap in body knowledge, it misses an early chance to provide evidence-based information about female genital structure and function.

\section{Girls Talk About "Down There"}

Of many topics related to the sexual behaviors and attitudes of those under 18, we focus here on girls' thoughts about engaging in oral sex. These yield important and specific information about their attitudes toward their own genitalia. We draw from two sources, heavily cited. Neither claim generalizability, but instead give voice to girls' own views. One is a peer-reviewed study of the oral sex experiences of 98 girls aged 12-17 (Burns, Futch, and Tolman 2011). A second, intended for the lay public, is Orenstein's (2016) report of her own journalistic investigation of girls' sex lives more broadly, from interviews with more than 70 girls and young women aged 15-20. We note, regrettably, that this material reflects the thoughts and experiences of heterosexual girls with male partners. More research is needed about the sexual (and menstrual) experiences of lesbian, bisexual, and transgender youth under 18 .

\section{Giving and Receiving (or Not) Oral Sex}

In both sources, girls discussed how and when to perform oral sex on males, and what they felt about doing it. Girls acknowledged an expectation to do it. One explained: "It's always the same unspoken sequence . . . You make out, then he feels you up, then you give him head, and that's it" (Orenstein 2016, 58). Another said: “. . . there's pressure for girls to do it. So it's about how comfortable you are with resisting that pressure or not. It gets awkward to keep resisting" (Orenstein 2016, 58). Further, Orenstein's (2016) participants thought oral sex wasn't a big deal, wasn't sex (sex was sexual intercourse), and was safer than sex because girls weren't giving up their virginity, couldn't get pregnant, or get sexually transmitted infections.

In contrast, girls mentioned avoiding receiving oral sex, relating their reluctance to discomfort with and dislike of their own genital area. Given girls' ready access to current genital appearance norms, and the lack of 
information about the wide variation in female genital appearance, their genital dissatisfaction is not surprising. In a discussion with two girls, one said she'd "rather have sex before I'd do that" (Orenstein 2016, 63). Another who gave her boyfriend oral sex said she

... never felt comfortable for him to return the favor. Because . . . okay this is weird to say, but a guy going down on you is more like a sacred thing. Like once you've done that, you must be really comfortable with the person, because it is not something that I'm just going to let you do ... A guy is totally aware of what he looks like "down there" . . . but I don't know what they're seeing on me. I can't see it. (Orenstein 2016, 63)

When Orenstein $(2016,63)$ suggested "Well . . there are these things called mirrors ...." this interviewee replied: "Yeah ... I'm not going to do that." Both girls were averse to seeing their own genitals.

Another, who prided herself on giving oral sex, was more direct. She offered that her boyfriend didn't want to do it and she'd never asked because "I don't like my vagina . . . I know that sucks. And I don't know why it should be so different, but I've internalized the idea" (Orenstein 2016, 63). Another, who self-identified as a feminist, said that when she received oral sex from her boyfriend, it was his idea:

It was not fun for me. I was not comfortable with it at all. I guess I've never been comfortable with my parts "down there." It's not something I find attractive. So I don't like the idea of someone else "down there." (Orenstein 2016, 65)

Girls also mentioned potentially being embarrassed and teased by boys about

. . . a fart with your vagina [featured on South Park] . . now teenage boys have that as something they can say about girls and girls know they have that so you feel awkward . . . It's just there's this whole culture around making fun of female sexuality, you know? And it's super strong. (Orenstein 2016, 63-64)

Additionally, most of Orenstein's interviewees shaved or waxed their public hair, many since age 14 . They never questioned it because they were already shaving their underarms and legs, and they'd seen older girls who were hairless. Girls also said it made them feel cleaner. Some mentioned that they shaved their public hair to avoid embarrassment, because they believed boys were disgusted by seeing it. Interestingly, neither Orenstein (2016) nor Burns, Futch, and Tolman (2011) reported comments from girls about encountering boys' pubic hair when giving oral sex.

Other thoughts about performing oral sex included describing it as a way to gain social status, or “. . . make friends with popular guys ... It's how you rack up points for hooking up with someone without having to actually have sex" (Orenstein 2016, 54). Some mentioned using oral sex to avoid sexual intercourse in a hook up: “. . . if he expects and wants to be satisfied [but] 
I want him to leave and I don't want anything to happen . . ." (Orenstein $2016,54-55)$. Some girls recognized a lack of reciprocity related to oral sex:

It's just expected that guys will get off . . . and then maybe he'll be like, 'Oh, do you want me to ...?' It's never like he'll do something for me and maybe I'll do something for him. It's like naturally I do something and then he'll ask if I 'want' him too. (Orenstein 2016, 61)

Others linked the lack of reciprocity in oral sex to not expressing their own desires. One said: “It goes back to girls feeling guilty. If you go to a guy's room and are hooking up with him, you feel bad leaving him without pleasing him in some ways" (Orenstein 2016, 55). Another added: "I don't think girls are taught to express their wants. We're these docile creatures that just learn to please" (Orenstein 2016, 58). One noted a disconnect between being a strong assertive female in other arenas, but not in terms of sexual behavior: "I think I didn't realize . . . I guess no one ever told me that the strong female image also applies to sex" (Orenstein 2016, 58).

Did girls enjoy performing oral sex? One of Orenstein's $(2016,56)$ participants mentioned that it was "sort of fun getting in the rhythm of it . .." but she also said that the physical part of it was "gross" and really hurt her throat: “. . . it's never fun fun." Girls interviewed by Burns, Futch, and Tolman (2011) also mentioned physical discomfort when performing oral sex. When asked about whether they themselves experienced excitement below the neck, girls offered no comments at all.

Girls interviewed by Burns, Futch, and Tolman (2011) mentioned being scared about not knowing how to do it and worrying about whether they would do it right. To get started, one girl described just doing it, like doing homework or taking a test, taking that first step, keeping on going, and then, finally, being finished. Eventually, with practice, and thinking about it while doing, girls did learn to do it. One said “. . . it wasn't intimate at all . . . It was more of, um, like an instructional video (laughs) I swear" (Burns, Futch, and Tolman 2011, 246). Some girls commented that they felt a sense of accomplishment in having learned how to give oral sex but even so, Burns, Futch, and Tolman $(2011,247)$ concluded that giving oral sex is not an "embodied experience for girls, but a cerebral one."

Girls willingness to learn how to give oral sex, even though finding it uncomfortable, even painful, and not particularly enjoyable, begs further analysis about agency, choice, and giving and receiving pleasure. That girls are much less interested in or even willing to receive oral sex seems, at least in part, due to their disdain for their own, but not boys' "down there."

\section{Revisioning Menstrual Education}

We take girls' comments as an opening to consider how preparation for menstruation can present young girls with accurate information about female genitalia as a foundation to buffer genital appearance and sexual expectation 
norms. Preparation for menstruation occurs in the context of approaching adolescence when changes in physical growth will be accompanied by sexual feelings and explorations. What better time to provide girls with a new vision of "down there," one that goes beyond a cursory explanation of menstruation and how to manage it, to one presenting a broader view of the cycle related to many aspects of health, including the healthy sexuality?

Such a revisioning of menstrual education first requires an acknowledgment of current cultural views of menstruation. Despite activist efforts to offset it (Bobel 2018; Fahs 2016; Weiss-Wolf 2017), stigma associated with menstruation, including menstrual sex as taboo (Fahs 2011, 2014), is still widespread throughout the world (Chrisler and Johnston-Robledo 2018; Dutta et al. 2016; Sommer et al. 2016). Negative views and representations of menstruation are not lost on adolescents or younger girls, who are avid readers of materials for adults (Stubbs 2008) and accomplished users of the internet (for example, Guttmacher Institute 2017). Especially during the transition from childhood to adolescence, girls become increasingly aware of cultural messages about both gender role expectations and discriminatory treatment of girls and women. They are vulnerable to espousing them, sometimes in conflict with their own views (Brown and Gilligan 1992; Piran 2017). With respect to menstruation, girls face a developmental dilemma-how to accept it as normative in the context of persistent menstrual stigma.

Given this situation, we now critique specific aspects of menstruation education gleaned from an exploratory review of 40 available books providing information on menstruation first undertaken by one of us (Stubbs 2013). Books were found in the children's section of a library located in an urban mid-Atlantic city, recommended by colleagues, or listed on several commercial websites such as Amazon.com. Since, we have perused updated versions of some reviewed in the original set and some more recent books for girls on the market.

\section{How Menstrual Education Shortchanges Girls}

\section{Puberty as Problematic}

Because information about menstruation is almost exclusively presented within a broader discussion of puberty, descriptions of puberty set the stage for information to follow. Unfortunately, puberty is often described as problematic-a time of upheaval and being out of control. Further, in descriptions of pubertal changes hormones are emphasized as in control, not girls themselves. While hormones are integral to pubertal processes, their role is often overdone and sensationalized. Hormones are described as racing around the body which girls can do nothing about (Thomas 2011). Rue (1995, 13) states: "What can I do about hormones? Well, nothing." Movsessian $(2004,25)$ fuels girls' powerlessness in the face of hormones and discourages the possibility of thinking about any other causes for their feelings or behavior: 
Girls, when in doubt blame it on the hormones. I'm in a bad mood? It's the hormones. I want to eat that big slab of chocolate cake? It's the hormones. I'm getting oilier skin, hair and pimples? But of course, all together now, 'It's the hormones!' . . . You may start off being a mild-mannered little girl, minding your own business, getting on with things and then what happens? You fill out, get hairs growing all over the shop, get boobs and become . . . a puberty girl.

These introductory messages foreshadow uncertainty and incapacity as girls move forward to learn about menstruation and other pubertal events.

\section{PMS: A Ubiquitous Cluster of Negative Symptoms}

Negative physical and emotional symptoms (bloating, breast tenderness, acne, cramps, fatigue, irritability, and sadness) are mentioned as common menstrual experiences and typically categorized together as premenstrual syndrome (PMS). In the American Girl's Care and Keeping of You for younger girls aged eight to ten, Schaefer $(2012,76)$ explains:

What is PMS? Once you begin to menstruate regularly you may notice some patterns in how you feel right before your period. Sometimes these physical and emotional symptoms are referred to as premenstrual syndrome or PMS for short. It's not a disease or an illness, just a natural part of your menstrual cycle.

Using the word "symptom" and naming the clustering of "symptoms" as a "syndrome" is problematic. These terms prime girls to associate these experiences with illness (Chrisler 1996). The assertion that these "symptoms" do not indicate illness or disease contradicts common usage of these terms and is confusing. Presenting negative "symptoms" in a defined category is especially problematic for younger girls since as concrete thinkers (Berger 2017) they are not yet cognitively able to critically evaluate this information.

The American Medical Association's Girl's Guide to Becoming a Teen also asserts that PMS symptoms are normal, but advises that ". . . it's important not to let them ruin your day (or your week!)" (Middleman and Pfeifer 2006, 71). This comment encourages girls to distance themselves from paying attention to their own experience, that is, by not thinking about it. Thomson (1995) goes a bit further suggesting that to deal with PMS, girls put things off until after their periods, thus undermining girls' agency and underscoring "loss-of-control" messages.

Finally, while many sources mention that hormones cause PMS, its etiology is still not clear (Hofmeister and Bodden 2016; Fisher et al. 2016). Also not mentioned are psychosocial factors which have been explored as contributors to PMS (King and Ussher 2012; Read, Perz, and Ussher 2014; Ussher and Perz 2013). 


\section{What's Normal and What's Not?}

Some sources suggest that there is no normal way to have a period. Marzollo $(1989,3)$ writes: "There is no perfectly normal way to have your period. Instead there are lots of normal ways, and your way is one of them." Bloom $(2017,19)$ offers: "You'd be surprised how much is considered 'in the range of normal' when it comes to puberty." Yet juxtaposed is often at least a brief description of the "average" period which happens about every 28 days, includes 3-5 days of bleeding, and about six tablespoons of total blood loss. Thus, girls receive a double message: there is an average, "normal" period which includes PMS as likely, but one's unique menstrual experiences are also normal. How are young girls, especially concrete thinkers, to judge their own experience, in the context of these contradictory messages? Further, in the absence of detail about severity, how is a girl to judge when her experiences are important enough to be concerned about, when the primary message is that these changes are normal?

The notion that "there is no normal" may serve to reassure girls that there is a lot of variation in menstrual experience, which is certainly true. However, clinicians themselves acknowledge that it is difficult to diagnose serious underlying conditions in adolescents because menstrual cycles can take 2-3 years to become established in an individual (Hofmeister and Bodden 2016), and we must add, do not necessarily standardize to the parameters of the "average" period. Moreover, clinicians who assume that anything goes in early menstrual life may themselves not consider these experiences as problematic (Hillard 2014).

Two aspects of early menstrual experience often presented as normal, cramps, and irregularity, should be further considered. Gravelle and Gravelle (2006, 36) write: "Although cramps are uncomfortable, they don't mean that anything is wrong." Regarding irregularity, Dickerson $(2005,118)$ suggests that "For some girls being irregular is just part of who they are." Clear clinical guidelines do exist describing what's normal and not related to menstruation (Hillard 2014), including information about cramps and irregularity. These data warn that severe cramping or dysmenorrhea can indicate endometriosis (Hickey and Balen 2003; Hillard 2014). Similarly, cycle lengths lasting for more than 90 days, should be further investigated since irregularity can indicate polycystic ovarian syndrome, primary ovarian insufficiency, eating disorders and female athletic triad (Hillard 2014).

Also problematic is the alarmist language often used. For example, concerning toxic shock, Plaisted $(2011,24)$ warns (original emphasis):

Most Important-tampons MUST be changed every few hours and should NEVER be left in the vagina for longer than eight hours. If you do, in rare cases, girls can develop something called Toxic Shock Syndrome, which will need urgent medical treatment. 
Because they are salient, alarmist messages will stand out amid other information and can elicit girls' thoughts about personal vulnerability. The younger the reader, the less likely she will be able to think critically about such warnings.

\section{Problematic Graphics and Stylistic Devices}

The imagery in many menstrual educational materials can also be problematic. Many sources represent girls as cartoon figures, but some do not present varied body types. For example, while both slimmer and heavier girls were easily identified in figures presented in the older edition of the American Girls' Body Book for Girls (Schaefer 1998), in the newer version the drawings barely differentiate these body types (Schaefer 2012). At least varying ethnicities are now more often represented than not (including Schaefer 1998, 2012), but given the wide variety of body shapes and sizes among pre-menarcheal girls, those who can't identify their body type in these books may not see this material as relevant to them. When these representations include diagrams of internal or external genitalia, or how menstrual management products are used, they generally do not offer an accurate view of the size or location of these organs relative to a real girl's body. While the stand-alone line drawings or diagrams of the internal and external genitalia in many sources present a "standardized" view with accurate labels of the various parts, nowhere were representations or discussion of the wide variety of female external genital appearance.

Cartoon-bubble inserts or sidebars are also often used to explain a concept. The latter, as well as catchy chapter titles, are likely to appeal to young audiences but also often include stereotypically negative messages about menstruation. For example, Bailey (2016, 40-41) includes sidebar titles such as "Period Panic - No 1: Painful Periods" and "Period Panic - No 2: PMT [more commonly referred to as PMS]." Bloom $(2017,77)$ titles her chapter on menstruation "Shark Week."

\section{No Mention of Menstruation as a "Vital Sign"}

The most important failure of menstrual education is the omission from all materials reviewed that menstruation is a "vital sign" of general health to be considered along with body temperature, blood pressure, heart, and respiration rates. This perspective goes beyond stating that "menstruation is normal." First advanced over ten years ago by medical professionals, it has recently been reaffirmed by both the American Academy of Pediatrics (AAP) (2016) and ACOG's Committee on Adolescent Health Care (2015). Despite of the efforts of a committed few (for example, Hillard 2014), this perspective has not found its way into public discourse, menstrual education or even public health outreach. 
Sterling (2018; Sterling, Karczmarczyl, and Ivabze 2017) has investigated the extent to which the menstrual cycle has been considered in core areas and outreach within public health initiatives, and finds it missing. She notes that menstrual management product manufacturers provide much of the menstrual education in schools but no program to evaluate their effectiveness. Critiques of these materials have long noted their presentation of mostly negative representations of menstruation (Johnston-Robledo and Chrisler 2013) and their continued emphasis on concealment and secrecy (Chrisler and Johnston-Robledo 2018). The omission of menstruation as a vital sign denies girls information about menstrual health and how that relates to other aspects of health and well-being, leaving the depiction of menstruation as a miserable menace unchallenged.

\section{Toward a More Positive View of Menstruation AND "DOwn There"}

We judge no one source as wholly negative. Rather, many sources include both problematic and admirable content and approaches to presentations of material. The problem is that no coordinated, evidence-based standards seem to guide what might be most helpful to girls about menstruation. Imagine what it might be like to create menstrual education content using evidence-based information about menstrual health as opposed to menstrual illness, acknowledging potential problems in a neutral way, and adjusting for cognitive ability and what we think of as a developmentally considered "need to know." Where is an evidenced-based scope and sequence chart of facts and concepts related to menstrual education? It has yet to be developed. Imagine, too, using menstruation as a vital sign as a starting point for menstrual education. Such a reframing could help to redress the burden of negativity in current materials. Toward that end, some specific suggestions for improving menstrual education follow.

\section{Concerning Pubertal Change}

Descriptions of puberty should provide positive aspects of change and growth and avoid overemphasizing the scariness of change or how immediately it occurs. Some books for girls do present this perspective. Marzollo $(1989,38)$ writes:

One of the most amazing things your body does month after month, over and over again, is prepare to reproduce another human being. Although it is hoped that you won't use your reproductive system until you're truly ready to be a mother, knowing how amazing it is can give you new respect and even awe for yourself and your abilities. Such self-respect can help you in turn put menstruation into better perspective. 
Feinmann $(2004,7)$ offers:

Any big change can be scary. And let's face it, having your first period is probably the biggest change in your life so far . . . Knowing what to expect will help you feel more in control. When you're in control, you're less anxious and better able to enjoy life.

We suggest drawing attention to emerging agency and self-reflection as opposed to asserting an inevitable loss of personal control relegated instead to an exaggerated role for hormones. We also advocate the use of neutral as opposed to alarmist language. Indeed, some have found a way to describing toxic shock using neutral as opposed to alarmist language (Loulan and Worthen 2001; Middleman and Pfeifer 2006).

\section{Concerning PMS}

To replace the notion that PMS with its cluster of negative symptomatology is inevitable, we advocate following Chrisler's (1996) suggestion that potential menstrual-related experiences be articulated as changes instead of symptoms to avoid embedding menstruation within the context of illness. Positive premenstrual changes, which have been noted (King and Ussher 2012), can also be mentioned. Given that biomedical and psychological guidelines now suggest that premenstrual symptoms can persist even several days into one's menstruation (Hofmeister and Bodden 2016), the term 'premenstrual' is confusing to us, but may explain why anecdotally, we have noticed that PMS now seems to be a descriptor of both before and during at least part of one's menstrual cycle. We understand a need to mention PMS in some way in menstrual education materials, since the term is used so frequently both in research and by the public. Doing so, however, poses a challenge for educators who want to provide a neutral perspective that supports girls in reflecting on their own experiences as they enter menstrual life.

\section{Concerning Genital Appearance}

Many sources offer commentary on pubic hair, often featuring information about how to groom or eliminate it. Many imply that pubic hair grooming is a matter of personal preference in the absence of scant information about potential health consequences related to various methods of removal (DeMaria et al. 2014; Williamson 2015). These deserve more than a mere mention, again, couched in neutral, non-alarmist language. Including information about the variety of historical and cultural views on pubic hair (and body hair in general) can further help girls contextualize current and often changing beauty standards related to this aspect of genital appearance.

To help girls realize the size and shape of their internal genitalia, using pictures of actual girls instead of cartoon figures should be considered. 
Movsessian (2004) offers a clever way of presenting the internal organs. She superimposes a diagram of them on the abdomen of a fully clothed girl which shows the relative position and size of them more realistically than a stand-alone graphic. Pictures of real girls may make it easier for readers to engage with other content as well.

Finally, to encourage girls' acceptance for how their own genitals look, compared to how current beauty standards say they should look, representations of the wide variation in the appearance of the inner and outer labia and the clitoris should be presented as normative, along with information about historical, cultural, and biomedical preferences for how the shape and look of these parts of female anatomy are judged to be "acceptable" or not.

More discussion of alternative menstrual management products, such as menstrual cups, reusable pads, and menstrual underwear along with the standard pad and tampon examples is warranted, since very few books described these. This discussion could help girls think more about their genital area as they consider product choices. Inclusion here of information about environmental issues related to product manufacture and disposal, as well as their accessibility, or not, in the lives of girls worldwide would also be welcome.

\section{EfFective Approaches Do Exist}

We found a variety of effective approaches in the sources reviewed that we hope to see again in new menstrual education materials. For example, inclusions of how to address practical problems, such as starting a period without a pad or tampon handy, will appeal especially to concrete thinkers, but also to older adolescents who have faced this challenge. Opportunities for interaction-quizzes about content, suggestions for reflective journaling, ways to document one's own development, and ways to track one's periodencourage readers' self-reflection and provide them with an active role in learning. Some sources provide a glossary, which is a quick resource for girls who may later come across terms already explained but can't quite remember the details. Insights about menstrual attitudes and practices from history, mythology, and psychosocial research can help girls contextualize their own experience and serve as a platform for using critical thinking to ponder their own practices related to menstruating. Finally, vignettes and comments from a variety of girls about their experiences will include their voices among those of adult authors for consideration.

\section{Addressing Boys}

Some books include both girls and boys as the audience and offer the chance to learn about their own and others' pubertal changes. However, if these books present negative representations of menstruation, boys as well as girls will also be subject to them. Accurate information about menstruation 
targeted just to boys is woefully absent (Allen, Kaestle, and Goldberg 2010; Lee 2009; Peranovic and Bentley 2017) and should be increased. This suggestion prompts addressing the menstrual experiences of trans individuals. Although an explanation of transgender identity is mentioned in some sources, none reviewed address the menstrual needs of these youth. For example, these youth may desire concealment for safety reasons, and not see it as a reflection of stigma as it might be for cis girls.

\section{A Preface for Parents}

Many sources also include a preface addressing both girls and mothers. Others are to be read by both mother and daughter. These are helpful approaches that could facilitate communication between both. The newer version of Period! (Loulan and Worthen 2001) comes with a detachable guide for parents and includes information about an approach a man might take as a menstrual educator. This is most welcome since men have not often been thought of in this role (Erchull and Richmond 2015). There are also books intended exclusively for mothers and other adult educators, yet another genre entirely in which information about menstruation should also be carefully reviewed.

Do mothers, (or fathers) actually buy or use the library to provide books about menstruation and puberty for their daughters? Which ones? Do daughters read these and/or appreciate having them? Today's girls and boys may be most comfortable learning about puberty and menstruation via websites. While future research should explore the content and use of these websites, we believe that our recommendations for improving menstrual education should inform any content regardless of the genre or venue in which it is presented.

\section{CONCLUSION}

Sexuality is inextricably linked to menstruation in terms of biological function, which is also understood psychosocially later in development. Yet we shy away from articulating this link in part because talking about sex and sexuality with children is challenging. Parents have reported that menstruation's relationship to reproduction, thus sexuality, is a stumbling block (Stubbs and Johnston-Robledo 2013). Similarly, in more formal menstrual education only scant attention to the connection between reproduction, sexuality, and menstruation is offered (Stubbs 2008). While girls may be told that menstruation occurs when an egg is not fertilized, what fertilization is or how it happens, begs detail.

Articulating how menstruation, reproduction, and sexuality intersect within menstrual education is long overdue and doable. Sheffield's (1988) book is an example of how even young children can be introduced to this linkage. Hers is an artistic portrayal intentionally designed as a starting point to later discussions rather than an explanation of details about the menstrual 
cycle. As girls get older, more information on the intersection of menstruation, reproduction, and sexuality can be added. Existing developmentally sequenced sex education curricula (Breuner et al. 2016; Flores and Barroso 2017) could help in creating a similar developmental approach to menstrual education curricula, which, if implemented, might actually provide parents (and others) with a more gradual way to address some aspects of sex.

In the sequence of development, the more intense focus on the genital area necessitated by preparation for menstruation provides a most opportune context for adding more fact-based information about the process of menstruation along with frank and accurate pictures or depictions and descriptions of the structures and functions of the reproductive organs involved. Inclusion at this time can serve as a knowledge base for girls to access later when they begin to explore becoming sexual. Accurate words (and pictures) of girls' vulvas, labia, clitorises, and vaginas earlier on in their development can help to normalize naming these body parts, as opposed to referring to them vaguely as "down there." The power to name and know their own bodies can give girls the power to name their sexual desires when they occur. To the extent that improved menstrual education can provide girls with a more accurate view of their genitals and a fuller understanding of these parts of the body, they will be positioned as more fully informed to evaluate and respond to the demands of fashion and make decisions about genital presentation, as well as those related to expectations about their sexual behavior.

\section{REFERENCES}

AAP (American Academy of Pediatrics). 2016. "Menstruation in Girls and Adolescents: Using Menstruation as a Vital Sign." Pediatrics 137 (3): e20154480. https://doi.org/10.1542/peds.2015-4480.

ACOG (American College of Obstetrics and Gynecology), Committee on Adolescent Health Care. 2015. "ACOG Committee Opinion No. 651: Menstruation in Girls and Adolescents: Using the Menstrual Cycle as a Vital Sign.” Obstetrics \& Gynecology 126 (6): e143-146. https://doi.org/10.1097/ aog.0000000000001215.

- 2017. "ACOG Committee Opinion No. 686: Breast and Labial Surgery in Adolescents." Obstetrics and Gynecology 129 (1): el7-e19. https://www.acog. org/-/media/CommitteeOpinions/Committee-on-Adolescent-HealthCare/ co686.pdf?dmc $=1 \&$ ts $=20170217 \mathrm{~T} 0416002970$.

ACOG (American College of Obstetrics and Gynecology), Committee on Gynecologic Practice. 2007. “ACOG Committee Opinion No. 378: Vaginal 'Rejuvenation' and Cosmetic Vaginal Procedures." Obstetrics and Gynecology 110 (3): 737-38. https://doi.org/10.1097/01.AOG.0000263927.82639.9b.

Allen, Kathrine R., Christine E. Kaestle, and Abbie E. Goldberg. 2010. "More Than Just a Punctuation Mark: How Boys and Young Men Learn about Menstruation." Journal of Family Issues 32 (2): 129-56. https://doi.org/10.1177/0192513x10371609. 
APA (American Psychological Association), Task Force on the Sexualization of Girls. 2007. Report of the APA Task Force on the Sexualization of Girls. Washington, DC: American Psychological Association. http://www.apa.org/pi/women/programs/ girls/report-full.pdf.

Arora, Kavita S., and Allan J. Jacobs. 2016. "Female Genital Alteration: A Compromise Solution." Journal of Medical Ethics 42 (3): 148-54. https://doi.org/10.1136/ medethics-2016-103376.

ASAPS (American Society for Aesthetic Plastic Surgeons). 2014. "Cosmetic Surgery National Data Bank Statistics.” Aesthetic Surgery Journal 34, no. 1 (1 July): 1-20. https://doi.org/10.1093/asj/34.Supplement_1.1.

— 2015. "Cosmetic Surgery National Data Bank Statistics." Aesthetic Surgery Journal 35, no. suppl_2 (1 July): 1-24. https://doi.org/10.1093/asj/35. Supplement_2.1.

_. 2016. "Cosmetic Surgery National Data Bank Statistics." Aesthetic Surgery Journal 36, no. suppl_1 (1 May): 1-29. https://doi.org/10.1093/asj/36. Supplement_1.1.

ASPS (American Society of Plastic Surgeons). 2016a. 2016 National Plastic Surgery Statistics. https://www.plasticsurgery.org/documents/News/Statistics/2016/2016plastic-surgery-statistics-report.pdf.

— 2016b. Plastic Surgery Statistics Report. https://www.plasticsurgery.org/documents/News/Statistics/2016/plastic-surgery-statistics-full-report-2016.pdf.

Bailey, Jacqui. 2016. Sex, Puberty and All That Stuff. New York, NY: Barron's Educational Series.

Bay-Cheng, Laina Y. 2015. "Living in Metaphors, Trapped in a Matrix: The Ramifications of Neoliberal Ideology for Young Women's Sexuality.” Sex Roles 73 (7-8): 332-39. https://doi.org/10.1007/s11199-015-0541-6.

Berger, Kathleen S. 2017. The Developing Person through the Lifespan. 10th ed. New York, NY: Worth.

Bloom, Naama. 2017. Hello Flo: The Guide, Period. New York, NY: Dutton Children's Books.

Bobel, Chris. 2018. The Managed Body: Developing Girls of Menstrual Health in the Global South. London: Palgrave Macmillan.

Bowerman, Mary. 2017. "Increase in Labiaplasty as Women Strive for Normal Look." USA Today, March 3. https://www.usatoday.com/story/news/nationnow $/ 2017 / 03 / 02 /$ increase-labiaplasty-women-strive-normal-vaginas-what-doesnormal-vagina-look-like-surgery/98629662/.

Breuner, Cora C., Gerri Mattson, AAP (American Academy of Pediatrics) Committee on Adolescence, and AAP Committee on Psychosocial Aspects of Child and Family Health. 2016. "Sexuality Education for Children and Adolescents." Pediatrics 138 (2): e20161348. https://doi.org/10.1542/peds.2016-1348.

Brown, Lyn M., and Carol Gilligan. 1992. Meeting at the Crossroads: Women's Psychology and Girls' Development. Cambridge, MA: Harvard University Press.

Burns, April, Valerie A. Futch, and Deborah L. Tolman. 2011. “'It's Like Doing Homework': Academic Achievement Discourse in Adolescent Girls' Fellatio Narratives." Sexuality Research and Social Policy 8 (3): 239-51. https://doi. org/10.1007/s13178-011-0062-1.

Chrisler, Joan. C. 1996. "PMS as a Culture-Bound Syndrome." In Lectures on the Psychology of Women, edited by Joan C. Chrisler, Carla Golden, and Patricia D. Rozee, 107-21. New York, NY: McGraw Hill. 
Chrisler, Joan C., and Ingrid Johnston-Robledo. 2018. Women's Embodied Self: Feminist Perspectives on Identity and Image. Washington, DC: American Psychological Association.

Crawford, Mary, I-Ching Lee, Galina Portnoy, Alka Gurung, Deepti Khati, Pinky Jha, and Anajana C. Regmi. 2008. "Objectified Body Consciousness in a Developing Country: A Comparison of Mothers and Daughters in the US and Nepal." Sex Roles 60 (3-4): 174-85. https://doi.org/10.1007/s11199-008-9521-4.

Dakanalis, Antonio, Alix C. Timko, Masimo Clerici, Giuseppe Riva, and Giusepei Carrà. 2017. "Objectified Body Consciousness (OBC) in Eating Psychopathology: Construct Validity, Reliability, and Measurement Invariance of the 24-Item OBC Scale in Clinical and Non-Clinical Adolescent Samples." Assessment 24 (2): 252-74. https://doi.org/10.1177/1073191115602553.

DeMaria, Andrea, L., Marrisa Flores, Jacqueline M. Hirth, and Abbey B. Berenson. 2014. "Complications Related to Pubic Hair Removal." Journal of Obstetrics and Gynecology 210 (6): 528.el-528.e5. https://doi.org/10.1016/j.ajog.2014.01.036.

Dickerson, Karle. 2005. On the Spot: Real Girls on Periods, Growing Up and Finding Your Groove. Avon, MA: Adams Media.

Dutta, Devashish, Chandler Badloe, Hyunjeong Lee, and Sarah House. 2016. Supporting the Rights of Girls and Women through Menstrual Hygiene Management (MHM) in the East Asia and Pacific Region: Realities, Progress and Opportunities. Bangkok, Thailand: UNICEF EAPRO (East Asia and Pacific Regional Office). http://www.cswashfund.org/sites/default/files/MHM_Realities_Progress_and_ OpportunitiesSupporting_opti.pdf.

Erchull, Mindy J., and Katherine Richmond. 2015. "'It's Normal...Mom Will Be Home in an Hour': The Role of Fathers in Menstrual Education." Women's Reproductive Health 2 (2): 93-110. https://doi.org/10.1080/23293691.2015.1 089149.

Fahs, Breanne. 2011. "Sex during Menstruation: Race, Sexual Identity, and Women's Accounts of Pleasure and Disgust." Feminism \& Psychology 21 (2): 155-78. https://doi.org/10.1177/09593535103966674.

- 2014. "Genital Panics: Constructing the Vagina in Women's Qualitative Narratives about Pubic Hair, Menstrual Sex, and Vaginal Self-Image.” Body Image 11 (3): 210-18. https://doi.org/10.1016/j.bodyim.2014.03.002.

- 2016. Out for Blood: Essays on Menstruation and Resistance. Albany, NY: State University of New York Press.

Feinmann, Jane. 2004. Everything a Girl Needs to Know about Her Periods. Portland, ME: Ronnie Sellers Productions.

Fine, Michelle. 1988. "Sexuality, Schooling, and Adolescent Females: The Missing Discourse of Desire." Harvard Educational Review 58 (21): 29-54.

Fisher, Carole, David Sibbrit, Louise Hickman, and Jon Adams. 2016. "A Critical Review of Complementary and Alternative Medicine Used by Women with Cyclic Perimenstrual Pain and Discomfort: A Focus Upon Prevalence, Patterns and Applications of Use and Users' Motivations, Information Seeking and Self-Perceived Efficacy." Acta Obstetricia et Gynecologica Scandinavica 95 (8): 861-71. https://doi.org/10.1111/aogs.12921.

Flores, Dalmacio, and Julie Barroso. 2017. "21st Century Parent-Child Sex Communication in the United States: A Process Review." Journal of Sex Research 54 (4-5): 532-48. https://doi.org/10.1080/00224499.2016.1267693. 
Fortenberry, J. Dennis. 2014. "Sexual Learning, Sexual Experience, and Healthy Adolescent Sex Behavior." Positive and Negative Outcomes of Sexual Behavior: New Directions for Child and Adolescent Development 2014, no. 144 (Summer): 71-86. https://doi.org/10.1002/cad.20061.

Goodman, Michael P., Otto J. Placik, David L. Matlock, Alex F. Simopoulos, Teresa A. Dalton, David Veale, and Susan Hardwick-Smith. 2016. "Evaluation of Body Image and Sexual Satisfaction in Women Undergoing Genital Plastic/Cosmetic Surgery." Aesthetic Surgery Journal 36 (9): 1048-57. https://doi.org/10.1093/ asj/sjw061.

Gravelle, Karen, and Jennifer Gravelle. 2006. The Period Book: Everything You Don't Want to Ask (But Need to Know). New York: Walker \& Company.

Guttmacher Institute. 2017. "American Adolescents' Sources of Sexual Health Information." New York, NY: Guttmacher Institute. https://www.guttmacher. org/fact-sheet/facts-american-teens-sources-information-about-sex.

Hardwick-Smith, Susan. 2011. "Examining the Controversy in Aesthetic Vaginal Surgery." American Journal of Cosmetic Surgery 28 (3): 106-13. https://doi. org/10.1177/074880681102800302.

Hickey, Martha, and Adam Balen. 2003. "Menstrual Disorders in Adolescence Investigation and Management." Human Reproduction Update 9 (5): 493-504. https://doi.org/10.1093/humupd/dmg038.

Hillard, Paula J. A. 2014. "Menstruation in Adolescents: What Do We Know? And What Do We Do with the Information?" Journal of Pediatric \& Adolescent Gynecology 27 (6): 309-19. https://doi.org/10.1016/j.jpag.2013.12.001.

Hofmeister, Sabrina, and Seth Bodden. 2016. "Premenstrual Syndrome and Premenstrual Dysphoric Disorder.” American Family Physician 94 (3): 236-40. http://www.gamgemai.co/Premenstrual\%20Syndrome\%20and $\% 20$ Premenstrual\% 20Dysphoric\%20Disorder.pdf.

Johnston-Robledo, Ingrid, and Joan C. Chrisler. 2013. "The Menstrual Mark: Menstruation as Social Stigma." Sex Roles 68 (1-2): 9-18. https://doi. org/10.1007/s11199-011-0052-z.

Johnston-Robledo, Ingrid, Kristin Sheffield, Jacqueline Voight, and Jennifer Wilcox-Constantine. 2007. "Reproductive Shame: Self-Objectification and Young Women's Attitudes toward Their Reproductive Functioning." Women \& Health 46 (1): 25-39. https://doi.org/10.1300/j013v46n01_03.

Johnston-Robledo, Ingrid, Melissa Ball, Kimberly Lauta, and Ann Zekoll. 2003. "To Bleed or Not to Bleed: Young Women's Attitudes toward Menstrual Suppression.” Women \& Health 38 (3): 59-75. https://doi.org/10.1300/j013v38n3_05.

King, Marlee, and Jane M. Ussher. 2012. "It's Not All Bad: Women's Construction and Lived Experience of Positive Premenstrual Change." Feminism and Psychology 23 (3): 399-417. https://doi.org/10.1177/0959353512440351.

Lamb, Sharon, and Zoë D. Peterson. 2012. "Adolescent Girls' Sexual Empowerment: Two Feminists Explore the Concept.” Sex Roles 66 (11-12): 703-12. https://doi. org/10.1007/s11199-011-9995-3.

Lee, Janet. 2009. "Bodies at Menarche: Stories of Shame, Concealment, and Sexual Maturation.” Sex Roles 60 (9-10): 615-57. https://doi.org/10.1007/ s11199-008-9569-1.

Lloyd, Jillian, Naomi S. Crouch, Catherine L. Minto, Lih-Mei Liao, and Sarah M. Creighton. 2005. "Female Genital Appearance: 'Normality' Unfolds.” BLOG: An 
International Journal of Obstetrics and Gynaecology 112 (5): 634-46. https://doi. org/10.1111/j.1471-0528.2004.00517.x.

Loulan, JoAnn, and Bonnie Worthen. 2001. Period: A Girl's Guide. Deephaven, MN: Book Peddlers.

Marzollo, Jean. 1989. Getting Your Period: A Book about Menstruation. New York: Dial Books for Young Readers.

Middleman, Amy B., and Kate G. Pfeifer. 2006. American Medical Association's Girl's Guide to Becoming a Teen. San Francisco, CA: Josey Bass.

Motakef, Saba, Jose Rodriguez-Feliz, Michael T. Chung, Michael J. Ingargiola, Victor W. Wong, and Ashit Patel. 2015. Systematic Review of Labiaplasty 135 (3): 774-88. https://doi.org/10.1097/prs.0000000000001000.

Movsessian, Shushann. 2004. Puberty Girl. Sydney, Australia: Allen \& Unwin.

Mowet, Hayley, Karalyn McDonald, Amy S. Dobson, Jane Fisher, and Maggie Kirkman. 2015. "The Contribution of Online Content to the Promotion and Normalization of Female Genital Cosmetic Surgery: A Systematic Review of the Literature." BMC Women's Health 15 (110). https://doi.org/10.1186/ s12905-015-0271-5.

Orenstein, Peggy. 2016. Girls and Sex: Navigating the Complicated New Landscape. New York, NY: Harper.

Peranovic, Tamara, and Brenda Bentley. 2017. "Men and Menstruation: A Qualitative Exploration of Beliefs, Attitudes and Experiences." Sex Roles 77 (1-2): 113-24. https://doi.org/10.1007/s11199-016-0701-3.

Piran, Niva. 2017. Journeys of Embodiment at the Intersection of Body and Culture: The Developmental Theory of Embodiment. Cambridge, MA: Academic Press.

Plaisted, Caroline A. 2011. Girl Talk. Irvine, CA: QEB Publishing.

Rabin, Roni C. 2016. "More Teenage Girls Seeking Genital Cosmetic Surgery." The New York Times, April 25. https://well.blogs.nytimes.com/2016/04/25/ increase-in-teenage-genital-surgery-prompts-guidelines-for-doctors /.

Read, Jennifer R., Janette Perz, and Jane M. Ussher. 2014. "Ways of Coping with Premenstrual Change: Development and Validation of a Premenstrual Coping Measure." BMC Women's Health 14 (9000). https://doi.org/ 10.1186/1472-6874-14-1.

Renganathan, Arasee, Rufus Cartwright, and Linda Cardozo. 2009. "Genital Cosmetic Surgery." Expert Review of Obstetrics o Gynecology 4 (2): 101-4. https://doi.org/10.1586/17474108.4.2.101.

Rue, Nancy. 1995. Everything You Need to Know about: Getting Your Period. New York, NY: The Rosen Publishing Group.

Schaefer, Valorie L. 1998. The Care and Keeping of You: The Body Book for Girls. Middleton, WI: American Girl Publishing.

- 2012. The Care and Keeping of You (Revised): The Body Book for Younger Girls. Middleton, WI: American Girl Publishing.

Schick, Vanessa R., Brandi Rima, and Sarah K. Calbrese. 2011. "Evulvalution: The Portrayal of Women's External Genitalia and General Physique across Time and the Current Barbie Doll Ideals." The Journal of Sex Research 48 (1): 74-81. https:// doi.org/10.1080/00224490903308404.

Sharp, Gemma, Marika Tiggeman, and Julie Mattiske. 2014. "Predictors of Consideration of Labiaplasty: An Extension of the Tripartite Influence Model of Beauty Ideas." Psychology of Women Quarterly 39 (2): 182-93. https://doi. org/10.1177/0361684314549949. 
Sheffield, Margaret. 1988. Life Blood: A New Image for Menstruation. New York, NY: Alfred A. Knopf.

Sommer, Marni, Bethany A. Caruso, Murat Sahin, Teresa Calderon, Sue Cavill, Therese Mahon, and Penelope A. Phillips-Howard. 2016. "A Time for Global Action: Addressing Girls' Menstrual Hygiene Management Needs in Schools." PLOS Medicine 13 (2): el001962. https://doi.org/10.1371/journal. pmed.1001962.

Sterling, Evelina W. 2018. "Menstrual Education in the United States: Opportunities for Improvement and Barriers to Change." Paper. The American Public Health Association. San Diego, CA, November 2018.

Sterling, Evelina W., Diana Karczmarczyl, and Irenose Ivabze. 2017. "Menstrual Health Is Public Health: The Importance of Menstrual Cycle Education.” Paper. The American Public Health Association. Atlanta, GA, November 2017.

Stubbs, Margaret L. 2008. "Cultural Perceptions and Practices Around Menarche and Adolescent Menstruation in the United States." Annals of the New York Academy of Sciences 1135 (1): 55-66. https://doi.org/10.1196/annals.1429.008.

. 2013. "Current Menstrual Education Resources: Still Room for Improvement." Paper. 20th Biennial Conference of the Society for Menstrual Cycle Research, June 2013.

Stubbs, Margaret L., and Ingrid Johnston-Robledo. 2013. "Kiddy Thongs and Menstrual Pads: The Sexualization of Girls and Early Menstrual Life." In The Sexualization of Girls and Girlhood: Causes, Consequences and Resistance, edited by Eileen L. Zurbriggen, and Tomi-Ann Roberts, 213-34. New York, NY: Oxford University Press.

Thomas, Isabel. 2011. Why Do I Have Periods? Chicago, IL: Raintree.

Thomson, Ruth. 1995. Have You Started Yet? Getting the Facts Straight. New York, NY: Pan Macmillan.

Tolman, Deborah, L. 2002. Dilemmas of Desire: Teenage Girls Talk about Sexuality. Cambridge, MA: Harvard University Press.

- 2012. "Female Adolescents, Sexual Empowerment and Desire: A Missing Discourse of Gender Equity." Sex Roles 66 (11-12): 746-57. https://doi. org/10.1007/s11199-012-0122-x.

Tolman, Deborah L., and Sara I. McClelland. 2011. "Normative Sexuality Development in Adolescence: A Decade in Review, 2000-2009." Journal of Research on Adolescence 21 (1): 242-55. https://doi.org/10.1111/j.15327795.2010.00726.x.

Tolman, Deborah L., Stephanie M. Anderson, and Kimberly Belmont. 2015. "Mobilizing the Metaphor: Considering the Complexities, Contradictions, and Contexts in Adolescent Girls' and Young Women's Sexual Agency." Sex Roles 73 (7-8): 298-310. https://doi.org/10.1007/s11199-015-0510-0.

Ussher, Jane M., and Janette Perz. 2013. "PMS as a Gendered Illness Related to the Construction and Relational Experience of Hetereo-Femininity. Sex Roles 68 (1-2): 132-50. https://doi.org/10.1007/s11199-011-9977-5.

Weiss-Wolf, Jennifer. 2017. Periods Gone Public: Taking a Stand for Menstrual Equity. New York, NY: Arcade Publishing.

Williamson, Heidi. 2015. "Social Pressures and Consequences Associated with Body Hair Removal." Journal of Aesthetic Nursing 4 (3): 131-33. https://doi. org/10.12968/joan.2015.4.3.131. 
Open Access This chapter is licensed under the terms of the Creative Commons Attribution 4.0 International License (http://creativecommons.org/licenses/ by $/ 4.0 /)$, which permits use, sharing, adaptation, distribution and reproduction in any medium or format, as long as you give appropriate credit to the original author(s) and the source, provide a link to the Creative Commons license and indicate if changes were made.

The images or other third party material in this chapter are included in the chapter's Creative Commons license, unless indicated otherwise in a credit line to the material. If material is not included in the chapter's Creative Commons license and your intended use is not permitted by statutory regulation or exceeds the permitted use, you will need to obtain permission directly from the copyright holder. 